\title{
1 Adolescents and school sport: The relationship between beliefs, social 2 support and physical self-perception
}

\author{
D.R. Lubans ${ }^{1 *}$, P.J. Morgan¹ and A. McCormack¹
}

* Corresponding author

8 David Lubans, PhD

9 University of Newcastle

School of Education

Email: David.Lubans@newcastle.edu.au

Telephone: +61 249212049

Fax: +61 249217407

Background: Physical activity declines during adolescence and strategies to combat this occurrence are both educational and public health priorities. Schools have been identified as central institutions for the promotion of physical activity among youth. While physical education is considered to be the major vehicle for physical activity promotion in the school setting, school sport provides another important opportunity to engage youth in physical activity. Little is known about students' beliefs about the value of school sport.

Purpose: The primary aim of this study was to explore the relationship between students' beliefs about school sport, social support received during school sport and physical self-esteem in adolescents. Participants and setting: The sample included 249 adolescents (126 boys and 123 girls) from ten secondary schools in New South Wales, Australia. The mean age of students was $14.1( \pm 1.6)$ years. Research design: Cross-sectional.

Data collection and analysis: Participants completed a detailed questionnaire assessing participation in school sport, school sport beliefs, perceived social support for school sport and physical self-esteem using the Physical Self-Perception Profile (PSPP). Independent samples t-tests were used to examine gender and age differences and hierarchical regression was used to determine the relationship between students' school sport beliefs, social support received during school sport and physical self-esteem. Separate analyses were conducted for boys and girls.

Findings: Both boys and girls considered school sport an important opportunity to be physically active. Students believed 'enjoyment' and selecting activities with their friends were the most important reasons for selecting school sport activities. Boys reported significantly higher levels of perceived physical strength $(F=1.58, p<0.05)$, sport competence $(F=0.28, p<0.000)$, physical condition $(F=$ 0.36, $p<0.01)$, body attractiveness $(F=1.76, p<0.01)$, and physical self-worth $(F=3.32, p<0.05)$. The model predicting boys' beliefs about school sport explained $17 \%$ of the variance $(F=4.08, p<$ $0.01)$ and the only statistically significant predictor was school sport social support $(\beta=0.25, p<0.01)$. Similarly, school sport social support $(\beta=0.31, p<0.01$ ) was also the only significant predictor in the girls' model which accounted for $28 \%$ of the variance in school sport beliefs $(F=6.46, p<0.001)$. Discussion: Students who recognised the value of school sport also reported higher levels of social support for school sport. School sport is an ideal opportunity for the promotion of physical activity and programs may be improved with increased diversity and choice for students. Furthermore, higher levels of teacher support and modelling may contribute to improved student outcomes for school sport programs.

Key words: Physical activity, school sport, attitudes, physical self-perception 


\section{Introduction}

2 While there has been debate about whether or not physical activity levels have

3 declined in the last 30 years (Westerterp \& Speakman, 2008), evidence suggests that the

4 current generation of children and adolescents accumulate less incidental physical

5 activity and are less likely to engage in active transportation to school than previous

6 generations (McDonald, 2007; Van der Ploeg, Merom, Corpuz, \& Bauman, 2008).

7 Moreover, there is compelling data to support the assertion that the largest decline in

8 physical activity over the lifespan occurs during adolescence (Kimm et al., 2002; Nader,

9 Bradley, Houts, McRitchie, \& O’Brien, 2008). Considering the well established benefits

10 of physical activity and the generational decrease in activity associated with

11 adolescence, the promotion of physical activity during this time period has emerged as

12 an important educational and public health objective.

13 Schools have been identified as important institutions for the promotion of

14 physical activity among youth (Biddle \& Mutrie, 2001; Centers for Disease Control \&

15 Prevention, 1997) and physical education (PE) has been recognised as the major vehicle

16 associated with the promotion of physical activity in the school setting (Wechsler,

17 Devereaux, Davis, \& Collins, 2000). While the role of PE in the promotion of physical

18 activity is well accepted (Daley, 2002; Fairclough, Stratton, \& Baldwin, 2002; Green,

19 2000; Sallis, 1991), youth physical activity recommendations cannot be met through the

20 PE curriculum alone. Additional opportunities for the promotion of physical activity in

21 schools include: recess and lunch breaks, the physical environment of schools, active

22 transportation, physical activity curriculum integration, extra-curricular activities and

23 school sport.

24 It is also accepted that extra-curricular activities and school sport have a role to

25 play in the promotion of activity in the school setting (Pate et al., 2006; Penney \& 
1 Harris, 1997; Ross, Hartford, Crawford, \& Miller, 1997). Primary and secondary

2 schools in many countries are required to provide students with weekly intra- and inter-

3 school sport programs. These programs are generally considered to be extra-curricular

4 as they take place beyond the school curriculum. Inter-school programs usually involve

5 team or individual competitions between schools, while intra-school programs are

6 competitive or non-competitive and consist of sports and a variety of recreational

7 activities within the one school. The delivery of school sport programs differs between

8 schools and the most common models of delivery in Australian schools are integrated,

9 scattered and traditional. The integrated sport model involves individual classes

10 timetabled throughout the week with specialist physical education or qualified staff

11 delivering the sessions. Scattered sport is organised so that year groups are timetabled to

12 have sport at the same time to enable specialist staff from both the school (i.e. physical

13 education teachers) and community (i.e. trained instructors or coaches) to deliver

14 sessions. Traditional school sport is organised with the whole school having sport

15 together at the same time each week and involves non-specialist teachers along with

16 specialist PE teachers and community members providing instruction.

17 While little is known about students' beliefs about the value of school sport or

18 about the factors associated with positive school sport beliefs, numerous studies have

19 explored students’ beliefs about PE (e.g. Flintoff \& Scraton, 2001; Rajmund, 2008;

20 Rikard \& Banville, 2006; Wang et al., 2008). Examining beliefs is important as

21 individuals personify the perceptions they hold about phenomena, and as a result these

22 influence behaviour (Bandura, 2004). Accordingly, the current study has been

23 conceptualised accepting the underlying principles and theoretical framework proposed

24 by Bandura $(1977,1986)$. Bandura’s $(1977,1986)$ theory of social learning asserts that

25 an individual's attitudinal disposition will impact on his or her overt response toward 
1 the object, either directly or indirectly through mediating variables such as self-efficacy.

2 Unfavourable beliefs of school sport may negatively influence future participation in

3 physical activities outside of school (Fox, 1988).

$4 \quad$ Beliefs are one of the many factors that may influence physical activity decisions.

5 These factors are collectively referred to as 'correlates' or 'determinants' and

6 developing an understanding of them is considered a prerequisite for designing relevant

7 programs and policies (Sallis, Prochaska, \& Taylor, 2000). A recent review concluded

8 that physical activity was associated with a number of demographic, sociological and

9 psychological factors including parental education, attitudes, self-efficacy, goal

10 orientation/motivation, participation in physical education/school sports, family

11 influences, and friend support in adolescents (Van der Horst, Paw, Twisk, \& Van

12 Mechelen, 2007). In addition, a review of the physical activity correlates among

13 adolescent girls (Biddle, Whitehead, O'Donovan, \& Nevill, 2005) found that physical

14 self-perceptions and perceived competence were both correlates of physical activity.

15 Physical self-perception consists of numerous sub-domains (e.g. perceived body

16 attractiveness, perceived athletic competence, perceived strength and physical

17 condition) (Fox \& Corbin, 1989, 1990) and has been identified as a significant

18 contributor to global self-esteem among adolescents (Santrock, 2005). While the

19 importance of social support and physical self-perceptions to adolescent physical

20 activity has been established, little is known about how social support and physical

21 perceptions relate to beliefs about school sport.

22 The primary aim of this study was to explore the relationship between students'

23 beliefs about the value of school sport, perceived social support received during school

24 sport and physical self-esteem in adolescents. Secondary aims were to identify the types

25 of physical activities offered in school sport in Australian secondary schools, factors 
1 influencing students' decision making when selecting school sport options and students

2 beliefs of the role of school sport.

\section{Methods}

\section{Participants}

5 Ethics approval was obtained from the University of Newcastle, New South Wales

6 (NSW), Australia and the NSW Department of Education and Training research ethics

7 committees. Ten schools were randomly selected for the study by choosing every $4^{\text {th }}$

8 school from the complete list of secondary schools located in the Hunter Region and

9 Central Coast, New South Wales, Australia. An initial invitation letter was sent to the

10 school principals of the ten schools. Three schools declined to participate in the study

11 and they were replaced by additional schools selected randomly from the remaining

12 schools. One year 7 class and one year 10 class from each school were randomly

13 selected using a similar method. Year 7 and Year 10 students were included in the

14 sample as they represent students from the first year of secondary school and the final

15 year before school sport is no longer compulsory. Information and consent letters were

16 distributed to 532 students from Year 7 ( $1^{\text {st }}$ year of secondary school, age range $12-14$

17 years) and Year 10 ( $4^{\text {th }}$ year of secondary school, age range 15-18). The information

18 letters provided to the students explained that the study was designed to examine their

19 perceptions of school sport and how it contributed to their physical activity levels. A

20 total of 249 students returned signed consent letters and participated in the study,

21 representing a response rate of $47 \%$.

\section{Measures}

23 Students completed questionnaires which were administered by trained research

24 assistants in a classroom in exam conditions. The completion time for the questionnaire

25 was approximately 30 minutes. Participants provided the following demographic 
1 information: age, gender, country of birth and language spoken at home and the

2 questionnaire included the following sections:

3 Participation in school sport

Students were provided with an extensive list of activities commonly offered

5 for school sport and asked to indicate which of the activities they had completed as part

6 of school sport while at secondary school. Students were also provided with an

7 opportunity to list additional physical activities they had participated in during school

8 sport. Students were then asked to indicate what influenced their decisions to choose

9 certain activities by ranking their reasons from 1 (most important) to 8 (least important).

10 Reasons included- cost, convenience, enjoyment, friends, competition, staff member

11 supervising/teaching the activity, their ability in the sport or activity or the level of

12 physical activity involved in the activity. Students could also record additional reasons

13 for selecting school sport options and offer suggestions for how school sport at their

14 school could be improved.

15 Role of school sport

Students were asked to indicate what they perceived the role of school sport to

17 be, by ranking the roles from 1 (most important) to 5 (least important). The roles of

18 school sport included-rest from academic time, an opportunity to be physically active,

19 an opportunity to learn new skills, an opportunity to spend time with friends and an

20 opportunity to compete against other students or schools. Students were also provided

21 with an opportunity to record additional school sport roles.

\section{School sport beliefs}

The scale included five items relating to students' beliefs about the value of

24 school sport. Students responded to a 5-point Likert scale (1 = Strongly Disagree to $5=$

25 Strongly Agree). 'School sport...' was the common stem and the five items were: i) is 
1 about learning new skills, ii) has led to me increasing my physical activity levels, iii) is

2 enjoyable, iv) has led me to start a new sport or physical activity outside of school and

$3 \mathrm{v})$ promotes an active lifestyle. Higher scores indicate more positive beliefs about the

4 value of school sport. The internal consistency for the scale was acceptable ( $\alpha=0.74)$.

5 Social support for school sport

6 This scale included five items relating to students' beliefs about the

7 instruction and social support students received from teachers and instructors during

8 school sport. Students responded to a 5-point Likert scale $(1=$ Strongly Disagree to $5=$

9 Strongly Agree). 'During school sport my teacher/instructor...' was the common stem

10 and included the following items: i) appears enthusiastic about school sport, ii) teaches

11 me valuable movement skills, iii) participates in physical activity or sport with me, iv)

12 makes the activity enjoyable and v) encourages me to participate in the activity. The

13 internal consistency for the scale was acceptable $(\alpha=0.84)$. Higher scores indicate

14 higher levels of perceived social support.

15 Physical Self-Perception Profile

17 provide a measure of self-esteem in the physical domain (Fox \& Corbin, 1989, 1990).

18 The PSPP contains five, six-item subscales that measure the following components of

19 physical self-perception: sports competence, physical condition, strength, body

20 attractiveness and overall physical self-worth. The PSPP uses a four-choice structured

21 alternative format to minimise socially desirable responses. Participants must first

22 decide which of two statements best describes them and then must choose whether the

23 statement is 'sort of true' or 'really true' for them. Each item is scored from 1 (low-self-

24 perception) to 4 (high self-perception), providing a maximum score of 24 and minimum

25 score of six for each subscale. The validity of the PSPP has been established (Eklund, 
1 Whitehead, \& Welk, 1997) and the internal consistency of the subscales in the study

2 sample were as follows: sports competence $(\alpha=0.77)$, physical condition $(\alpha=0.86)$,

3 strength $(\alpha=0.79)$, body attractiveness $(\alpha=0.80)$ and overall physical self-worth $(\alpha=$ 4 0.68).

5 Piloting of questionnaire

6 The study questionnaire was extensively piloted with 65 students from

7 secondary schools not involved in the current study. Following the piloting process a

8 number of modifications were made to the questionnaire. First, additional open-ended

9 questions were added to provide students with an opportunity to extend upon the

10 answers they provided. Second, two questions were restructured to enable respondents

11 to rank the importance of responses. Finally, a number of items were removed from the

12 original school sport beliefs and social support scales because they did not provide

13 adequate loadings to the proposed factors after the confirmatory factor analysis.

\section{Analysis}

15 Data were analysed using the Statistical Package for the Social Sciences (SPSS, version

16 16, SPSS Inc., Chicago, Ill, USA) and alpha levels were set at $p<0.05$. All data were

17 assessed for normality and satisfied the criteria. Structural equation modelling (SEM) in

18 AMOS (version 16, SPSS Inc., Chicago, Ill, USA) was used to examine the

19 psychometric properties of the school sport beliefs and social support scales developed

20 for the current study. Confirmatory factor analysis (CFA) using maximum likelihood

21 estimation was used to examine scale consistency and discriminant validity of the two

22 scales. Independent samples t-tests were used to compare gender and age (i.e. Year 7

23 versus Year 10) differences for all relevant variables. Bivariate correlation was used to

24 examine the relationship between psychological constructs for boys and girls separately.

25 Hierarchical regression was used to determine the relationship between students' school 
1 sport beliefs, social support received during school sport and physical self-esteem. Year

2 at school was entered in the first step, followed by social support. In the final step the

3 five constructs from the PSPP were entered into the regression model.

\section{Results}

5 The total sample included 249 students comprising 126 boys and 123 girls from ten

6 secondary schools. This included 134 Year 7 students and 115 Year 10 students. The

7 mean age of participants was $14.1( \pm 1.6)$ years and the majority were born in Australia

8 (97.8\%) and spoke English at home (98.4\%). Seven schools in the study sample

9 employed a traditional sport model whilst three schools used an integrated school sport

10 model.

11 Psychometric properties of school sport scales

A CFA using ML estimation on the covariance matrix of the ten items of

13 school sport beliefs and social support for school sport found that the data were an

14 excellent fit to the hypothesized two-factor model, $\chi^{2}(\mathrm{~N}=241, d f=34)=48.96$,

15 Bollen-Stine bootstrap $p=0.207$ (Figure 1). The factor loadings were significant at $p<$

160.001 and the standardised loadings ranged from 0.43 to 0.69 for the beliefs scale and

170.64 to 0.78 for the social support scale. Inspection of the structure coefficients for both

18 scales indicated a clear distinction between the items comprising the respective factors

19 (Table 1).

20 Participation in school sport

21 Boys and girls reported participating in a diverse range of activities including

22 traditional team sports and recreational lifetime activities. The six most common

23 activities for boys, in descending order were soccer (football), indoor soccer (indoor

24 football), touch football (touch rugby), basketball, cricket and tennis (Table 2). The

25 most common activities reported by girls were soccer (football), tennis, netball, 
1 basketball, swimming and cricket. For boys and girls the two most important reasons

2 for selecting a school sport option were 'enjoyment' and 'friends'. 'Level of physical

3 activity involved' and 'students' perceived level of skill and ability' were also salient

4 reasons for selecting school sport options. Almost one third of students $(n=81)$

5 suggested that school sport could be improved by providing a greater range of activities

6 to choose from. For example, 'To do more different types of sports, rather than your

7 everyday sports'. According to students, the time available for school sport and the cost

8 of school sport activities were also aspects of school sport that could be improved.

9 Role of school sport

Boys and girls both rated 'an opportunity to be physically active' as the

11 number one role of school sport. According to boys, other important roles of school

12 sport were 'a rest from academic time' and an 'opportunity to learn new skills'. For

13 girls, 'learning new skills' and 'spending time with friends' were important aspects of

14 school sport.

15 Gender and age differences in psychological constructs

$17225)=1.579, p<0.05]$, sport competence $[F(1,232)=0.278, p<0.001]$, physical

18 condition $[F(1,229)=0.359, p<0.01]$, body attractiveness $[F(1,226)=1.76, p<$

$190.01]$, and physical self-worth $[F(1,224)=3.32, p<0.05]$. There were no significant

20 differences between boys and girls for school sport beliefs $[F(1,241)=0.674, p=$

$210.766)$ or perceived social support for school sport $[F(1,242)=0.685, p=0.451)$.

22 Year 7 students reported higher levels of physical self-worth $[F(1,224)=$

$230.879, p<.01)$, physical condition $[F(1,229)=0.971, p<.01)$, body attractiveness $(F$

$24(1,226)=0.272, p<.05)$, physical strength $[F(1,225,=0.915, p<.05)$ and school

25 sport social support $[F(1,242)=0.107, p<.05)$. There were no significant differences 
1 between Year 7 and Year 10 students for sport competence $[F(1,232)=0.296, p=$

2 0.146] and school sport beliefs $[F(1,241)=0.151, p=0.747]$.

3 Relationship between psychological constructs

Bivariate correlations between psychological constructs are presented in Table

53 and Table 4 for boys and girls, respectively. In boys, social support for school sport

6 was associated with physical self worth $(r=0.20, p<0.05)$, sport competence $(r=$

$70.22, p<0.05)$, physical condition $(r=0.28, p<0.01)$, body attractiveness $(r=0.29, p$

$8<0.01)$, physical strength $(r=0.19, p<0.05)$ and school sport beliefs $(r=0.32, p<$

9 0.01). Stronger correlations were found between school sport beliefs and physical self-

10 esteem constructs. In girls, social support was associated with sport competence ( $r=$

$110.28, p<0.01$ ), but not with any of the other physical self-esteem constructs. The

12 relationship between school sport beliefs and social support for school sport was

13 moderate $(r=0.39, p<0.001)$,

14 The results of the regression model predicting students' beliefs of school sport

15 are reported in Table 5 for boys and Table 6 for girls. The model predicting boys’

16 beliefs about school sport explained $17 \%$ of the variance $(F=4.08, p<0.01)$ and the

17 only statistically significant predictor was school sport social support $(\beta=0.25, p<$

18 0.01). Similarly, school sport social support $(\beta=0.31, p<0.01)$ was also the only

19 significant predictor in the girls' model which accounted for $28 \%$ of the variance in

20 school sport beliefs for girls $(F=6.46, p<0.001)$. However, physical self-worth and

21 sport competence were marginally significant predictors of school sport beliefs in the

22 girls’ model $(0.05 \leq p<0.10)$.

23 Discussion

24 The primary aim of this study was to explore the relationship between adolescents'

25 school sport beliefs, social support received during school sport and physical self- 
1 esteem. Higher levels of perceived social support were associated with more positive

2 beliefs about the value of school sport for both boys and girls. While there were

3 moderate correlations between school sport beliefs and perceived sport competence in

4 boys and girls, these associations were not significant in the multiple regression models.

5 The study also sought to identify the activities engaged in during school sport and

6 students' reasons for choosing certain activities. The most common activities were

7 traditional team sports and the number of students participating in lifetime and

8 recreational activities was relatively small. Both boys and girls considered school sport

9 provided an opportunity to be physically active and 'enjoyment' and 'spending time

10 with friends' were the most important reasons for selecting school sport options.

11 An important finding from this study was that students, who perceived higher

12 levels of social support, encouragement, and motor skill development from their

13 teachers and instructors during school sport, exhibited more positive feelings about

14 school sport. Students with more positive feelings about school sport are more likely to

15 seek opportunities to be physically active. Although beliefs are generally not considered

16 to be direct predictors of physical activity, they may be important precursors to

17 important mediators of behaviour such as self-efficacy (Lubans, Foster, \& Biddle,

18 2008). Recent reviews of the correlates of physical activity in adolescents concluded

19 that social support from family and friends was associated with higher levels of physical

20 activity (Biddle et al., 2005; Van der Horst et al., 2007). However, studies that have

21 examined the relationship between teacher support and modelling and physical activity

22 have found no association (Biddle \& Goudas, 1996; Zakarian, Hovell, Hofstetter, Sallis,

23 \& Keating, 1994). It is possible that social support received during school sport is

24 related to activity level in school sport only, but not to overall physical activity levels.

25 Additional factors may facilitate and impede physical activity behaviour outside of the 
1 school setting. School sport is one of many opportunities for the promotion of physical

2 activity in the secondary school setting and the provision of increased social support

3 from teachers and instructors may contribute to increased physical activity and

4 enjoyment in adolescence.

5 'Enjoyment' and 'spending time with friends' were the most important reasons

6 for selecting school sport activities. Previous studies have found that enjoyment and

7 social support from friends are important correlates of physical activity among

8 adolescents (Biddle et al., 2005; Lubans \& Morgan, 2009; Van der Horst et al., 2007).

9 Unlike physical education, school sport generally provides students with an opportunity

10 to choose their own activities, which they can select with their friends. Finding ways to

11 enhance students' enjoyment, while supporting the social aspects of school sport, are

12 important considerations for teachers.

13 The regression models predicting school sport beliefs explained $17 \%$ and $28 \%$

14 of the variance for boys and girls, respectively. Additional explanatory variables may

15 need to be included in future models. Previous studies have linked actual motor

16 competence to physical activity among youth (Castelli \& Valley, 2007; Erwin \&

17 Castelli, 2008; Fisher et al., 2005; Okely, Booth, \& Patterson, 2001; Raudsepp \& Pall,

18 2006; Wrotniak, Epstein, Dorn, Jones K.E., \& Kondilis, 2006) and motor proficiency

19 might explain additional variance. This study has shown that school sport is dominated

20 by competitive team sports and it is plausible to suggest that students with higher levels

21 of motor proficiency also have more positive beliefs about the value of school sport. If

22 school sport is focused on team sport activities it is unlikely that students with lower

23 skill levels will enjoy the experience and develop positive beliefs about the value of

24 school sport. 
The majority of students reported engaging in competitive team sports for

2 school sport, which is consistent with previous studies that have explored students'

3 activities in physical education (Hill \& Cleven, 2005; Hill \& Hannon, 2008). Although

4 students generally follow a prescribed program of study in PE, the importance of

5 providing students with choice over curricular activities in PE has been proposed in the

6 literature (Hill \& Hannon, 2008). It is interesting to note that approximately one third of

7 the study sample suggested that their school sport program could be improved by

8 providing more choice and variety in the types of physical activities available. It has

9 been noted that school-based PE and school sport should progress from a focus on

10 general movement activity and skill development in primary schools to a focus on the

11 health, fitness and behavioural components of physical activity in the secondary school

12 setting (Strong et al., 2005). However, research suggests that PE and school sport are

13 dominated by competitive team sport activities (Fairclough et al., 2002; Hill \& Cleven,

14 2005; Hill \& Hannon, 2008; MacFadyen, 1999). The ten most common activities

15 reported by boys and girls included only two lifetime activities (i.e. swimming and

16 fitness activities). While it cannot be determined from the current study how many

17 lifetime activities were provided by schools and not selected by students, based on the

18 student responses to open-ended questions, it appears that students are dissatisfied with

19 the existing choices available.

Students also suggested that the time available for school sport and the cost of

21 school sport activities were aspects of school sport that could be improved. Although

22 school sport may not cost students in all countries (e.g. United Kingdom), in Australia,

23 many school sport options are only available to students willing and able to pay

24 additional fees. Those students unable to pay for transportation and/or entry to some

25 recreational activities (e.g. roller skating, health and fitness centre), are generally 
1 provided with traditional team sports as an alternative. As stated previously, it is

2 important that adolescents participate in a range of lifetime activities that will encourage

3 future participation. Schools have an important role to play in overcoming the barriers

4 to physical activity experienced by students from disadvantaged backgrounds. Similar to previous studies (Daley, 2002; Raustorp, Stahle, Gudasic,

6 Kinnunen, \& Mattsson, 2005) the boys in this study reported significantly higher levels

7 of physical self-esteem than the girls. Perceived sport competence was the only physical

8 self-esteem construct related to girls’ perceived social support. This is an interesting

9 finding and suggests that girls with higher levels of perceived sport competence also

10 perceive higher levels of social support during school sport. As discussed previously,

11 school sport is dominated by competitive team sports and highly skilled girls

12 participating in inter-school sport competitions may receive more social support than

13 girls participating in intra-school programs. The relationship between school sport

14 beliefs and sport competence was moderate for both boys and girls. Research suggests

15 that perceived lack of physical skill is a major barrier to participation in physical

16 activity among adolescents (Fairclough, 2003; Hill \& Hannon, 2008; Wallhead \&

17 Buckworth, 2004). A recent longitudinal study found that FMS competency in

18 childhood predicted physical activity in adolescence (Barnett, van Beurden, Morgan,

19 Brooks, \& Beard, 2009) and that the relationship was mediated by perceived sport

20 competence (Barnett, Morgan, van Beurden, \& Beard, 2008). It could be argued that the

21 current school sport focus on team sports may reward students with high levels of motor

22 proficiency. Individuals with higher levels of perceived and actual competence are more

23 likely to recognise games, sports and physical activities as enjoyable and seek

24 additional opportunities to be active (Fisher et al., 2005; Stodden et al., 2008).

25 Implications 
This study has important implications for the delivery of school sport

2 programs in the secondary school setting. First, it is important that teachers recognise

3 the importance of social support and role modelling in school sport. In Australian

4 schools many school sport activities are delivered by non-specialist teachers (i.e. not by

5 physical education teachers). Many of these teachers do not have adequate training and

6 experience to deliver high quality school sport programs and additional in-servicing and

7 professional development may assist these individuals. Without essential knowledge

8 and skills, non-specialist teachers may find it difficult to efficiently organise practical

9 activities and provide the necessary instruction and feedback to motivate students.

10 Furthermore, as the fear of public failure and embarrassment are powerful barriers to

11 participation in physical education and school sport programs (Biddle, 2001), it is

12 important that teachers recognise that students' efforts and abilities will be scrutinised

13 by others in the group. Teachers should be aware of the importance of perceived sport

14 competence and provide social support and opportunities for skill mastery. Furthermore,

15 teachers should embrace the social nature of school sport and encourage students to

16 choose activities that they can participate in with their friends. It is important that

17 schools find a balance between providing students with enjoyable active opportunities

18 and creating a social environment that will increase students' levels of intrinsic

19 motivation to enhance future participation. This may help students lacking in confidence

20 to overcome their anxieties about participation. Second, while school sport should build

21 upon and extend beyond the PE curriculum, it is important school sport remain distinct

22 from PE and provide students with diversity and an opportunity to engage in a variety

23 of 'lifetime' physical activities, such as health-related fitness and recreational activities.

24 A common criticism of PE is that students follow a set program and are given limited

25 opportunity to choose their activities. While adolescents generally have positive beliefs 
1 about physical activity, many students possess a negative attitude towards PE and

2 eventually develop negative attitudes to physical activity (Corbin, 2002). Finally, the

3 impact of school sport physical activity programs should be evaluated to determine the

4 types of activities and programs that contribute to improved activity levels and

5 cognitions relating to activity.

6 Strengths and limitations

This is the first study to explore the relationship between students’ beliefs

8 about the value of school sport, perceived social support and physical self-perceptions.

9 Moreover, the study involved a random sample of schools combined with randomly

10 selected classes from the study schools. However, there are a number of limitations in

11 the current study that should be noted. First, only schools in the Hunter Region and

12 Central Coast of New South Wales, Australia were included in this study, which may

13 limit the generalizability of the results. However, while the sample size was relatively

14 small, the random selection of schools and classes has provided a representative sample

15 of students from the region. Second, the study involved a cross-sectional design and

16 therefore causal relationships cannot be established. Third, the study did not assess

17 physical activity and therefore the relationship between social support, school sport

18 beliefs and physical activity cannot be determined. Finally, no school sport sessions

19 were observed to determine the actual level of social support provided by teachers.

20 Conclusions

21 This study has shown that students who report higher levels of social support

22 during school sport also report more positive beliefs about the value of school sport.

23 Perceived sport competence was moderately associated with school sport beliefs in

24 boys and girls. The majority of students reported participation in competitive team

25 sports and a third of students suggested that their school sport program could be 
1 improved with greater choice and diversity in the types of activities offered. Both boys

2 and girls considered school sport provided an opportunity to be physically active and

3 'enjoyment' and 'spending time with friends' were the most important reasons for

4 selecting school sport options. Secondary schools should consider these issues when

5 designing their school sport programs.

6 
1 Table 1: Item factor loadings to school sport beliefs and social support constructs

\begin{tabular}{lcc}
\hline \multicolumn{1}{c}{ Items } & \multicolumn{2}{c}{ Factors } \\
\cline { 2 - 3 } & School sport & School sport \\
social support & $\mathbf{0 . 7 2 8}$ & 0.341 \\
\hline 1) Appears enthusiastic about school sport & $\mathbf{0 . 7 6 8}$ & 0.360 \\
2) Teaches me valuable movement skills & $\mathbf{0 . 6 4 0}$ & 0.300 \\
3) Participates in physical activity or sport with me & $\mathbf{0 . 7 7 8}$ & 0.365 \\
4) Makes the activity enjoyable & $\mathbf{0 . 6 4 0}$ & 0.302 \\
5) Encourages me to participate in the activity & 0.308 & $\mathbf{0 . 6 5 7}$ \\
6) Is about learning new skills & 0.306 & $\mathbf{0 . 6 5 4}$ \\
7) Has led to me increasing my physical activity levels & 0.321 & $\mathbf{0 . 6 8 6}$ \\
8) Is enjoyable & 0.202 & $\mathbf{0 . 4 3 0}$ \\
9) Has led me to start a new sport or physical activity outside of school & 0.296 & $\mathbf{0 . 6 3 2}$ \\
10) Promotes an active lifestyle & & \\
\hline
\end{tabular}

3 
School Sport Beliefs

1 Table 2: Ten most common activities reported by boys and girls for school sport

\begin{tabular}{llll}
\hline \multicolumn{1}{c}{ Boys } & & \multicolumn{2}{c}{ Girls } \\
\hline \multicolumn{1}{c}{ Activity } & \% of students & \multicolumn{1}{c}{ Activity } & \% of students \\
\hline Soccer (football) & $57 \%$ & Soccer (football) & $50 \%$ \\
Indoor soccer (football) & $50 \%$ & Tennis & $46 \%$ \\
Touch football (rugby) & $46 \%$ & Touch football (rugby) & $46 \%$ \\
Basketball & $42 \%$ & Netball & $37 \%$ \\
Tennis & $35 \%$ & Volleyball & $36 \%$ \\
Cricket & $35 \%$ & Basketball & $35 \%$ \\
Oztag & & Cricket & $29 \%$ \\
Swimming & $33 \%$ & Oztag & $28 \%$ \\
Rugby league & $31 \%$ & Athletics & $27 \%$ \\
Fitness activities & $31 \%$ & Fitness activities & $26 \%$
\end{tabular}

2 aztag is a team game similar to touch football (rugby) and a tag is made when the defending player removes one of 3 two velcro stripes, known as tags, from the ball carrier's shorts. 
1 Table 3: Bivariate correlations between psychological constructs in boys

2 Variables

1

3

5

6

1. Physical self worth

2. Sport competence

$0.65^{* * *}$

3. Physical condition

$0.73^{* *}$

$0.78^{* * *}$

4. Body attractiveness

$0.68^{* * *} \quad 0.43^{* * *} \quad 0.66^{* * *}$

5. Physical strength

$0.54 * *$

$0.50 * *$

$0.45^{* * *}$

$0.56 * * *$

6. Social support for school sport

0.20 *

$0.22 *$

$0.28 *$

$0.29 *$

$0.19 *$

7. School sport beliefs

$0.29 * *$

$0.41^{* *}$

$0.42 * *$

$0.23 *$

$0.23 *$

$0.32 * *$

$3 * \overline{p<0.05,{ }^{* *} p<0.01,{ }^{* * *} p<0.001}$

4 
1 Table 4: Bivariate correlations between psychological constructs in girls

2

\begin{tabular}{lcccccc}
\hline Variables & $\mathbf{1}$ & $\mathbf{2}$ & $\mathbf{3}$ & $\mathbf{4}$ & $\mathbf{5}$ & $\mathbf{6}$ \\
\hline 1. Physical self worth & & & & & & \\
2. Sport competence & $0.51^{* * *}$ & & & & & \\
3. Physical condition & $0.69^{* * *}$ & $0.71^{* * *}$ & & & & \\
4. Body attractiveness & $0.58^{* * *}$ & $0.36^{* * *}$ & $0.55^{* * *}$ & & & \\
5. Physical strength & $0.53^{* * *}$ & $0.66^{* * *}$ & $0.74^{* * *}$ & $0.47^{* * *}$ & & \\
6. Social support for school sport & 0.04 & $0.28^{* *}$ & 0.14 & -0.08 & 0.06 & \\
7. School sport beliefs & $0.27^{* *}$ & $0.43^{* *}$ & $0.37^{* *}$ & -0.01 & $0.34^{* *}$ & $0.39^{* *}$ \\
\hline
\end{tabular}

$3{ }^{*} p<0.05,{ }^{* *} p<0.01,{ }^{* * *} p<0.001$

4 
1 Table 5: Hierarchical regression model predicting boys' school sport beliefs

\begin{tabular}{|c|c|c|c|}
\hline Blocks of variables & Variables & Significance level (p) & $\begin{array}{c}\text { Standardized } \\
\text { coefficients }(\boldsymbol{\beta})\end{array}$ \\
\hline \multirow[t]{2}{*}{ Step 1} & Adjusted $\mathrm{R}^{2}=0.001$ & 0.304 & \\
\hline & Year group & 0.304 & -0.099 \\
\hline \multirow[t]{3}{*}{ Step 2} & $\Delta$ adjusted $\mathrm{R}^{2}=0.087 * *$ & 0.003 & \\
\hline & Year group & 0.169 & -0.128 \\
\hline & Social support & 0.001 & 0.310 \\
\hline \multirow[t]{9}{*}{ Step 3} & $\Delta$ adjusted $\mathrm{R}^{2}=0.078^{* *}$ & 0.001 & \\
\hline & Year group & 0.415 & -0.075 \\
\hline & Social support** & 0.009 & 0.248 \\
\hline & Physical self-worth & 0.770 & -0.043 \\
\hline & Sport competence & 0.237 & 0.184 \\
\hline & Physical condition & 0.148 & 0.257 \\
\hline & Body attractiveness & 0.549 & -0.090 \\
\hline & Physical strength & 0.854 & 0.021 \\
\hline & Total adjusted $\mathrm{R}^{2}=0.166^{* *}$ & 0.001 & \\
\hline
\end{tabular}

2 Note. $\Delta$ adjusted $\mathrm{R}^{2}$ indicates the proportion of variance attributable to the blocks of variables.

$3 * p<0.05,{ }^{* *} p<0.01,{ }^{* * *} p<0.001$

4 
1 Table 6: Hierarchical regression model predicting girls’ school sport beliefs

\begin{tabular}{|c|c|c|c|}
\hline Blocks of variables & Variables & Significance level (p) & $\begin{array}{l}\text { Standardized } \\
\text { coefficients }(\beta)\end{array}$ \\
\hline \multirow[t]{2}{*}{ Step 1} & Adjusted $\mathrm{R}^{2}=0.009$ & 0.728 & \\
\hline & Year group & 0.728 & -0.036 \\
\hline \multirow[t]{3}{*}{ Step 2} & $\Delta$ adjusted $\mathrm{R}^{2}=0.158$ & 0.000 & \\
\hline & Year group & 0.703 & 0.037 \\
\hline & Social support & 0.000 & 0.433 \\
\hline \multirow[t]{9}{*}{ Step 3} & $\Delta$ adjusted $\mathrm{R}^{2}=0.112^{* *}$ & 0.000 & \\
\hline & Year group & 0.685 & 0.037 \\
\hline & Social support** & 0.001 & 0.310 \\
\hline & Physical self-worth & 0.081 & 0.222 \\
\hline & Sport competence & 0.095 & 0.222 \\
\hline & Physical condition & 0.687 & 0.063 \\
\hline & Body attractiveness & 0.063 & -0.214 \\
\hline & Physical strength & 0.638 & 0.064 \\
\hline & Total adjusted $\mathrm{R}^{2}=0.279 * *$ & 0.000 & \\
\hline
\end{tabular}

2 Note. $\Delta$ adjusted $\mathrm{R}^{2}$ indicates the proportion of variance attributable to the blocks of variables.

$3 * p<0.05,{ }^{* *} p<0.01,{ }^{* * *} p<0.001$

4

5 
1 Figure 1: Standardised parameter estimates of school sport beliefs and social

2 support scales

3

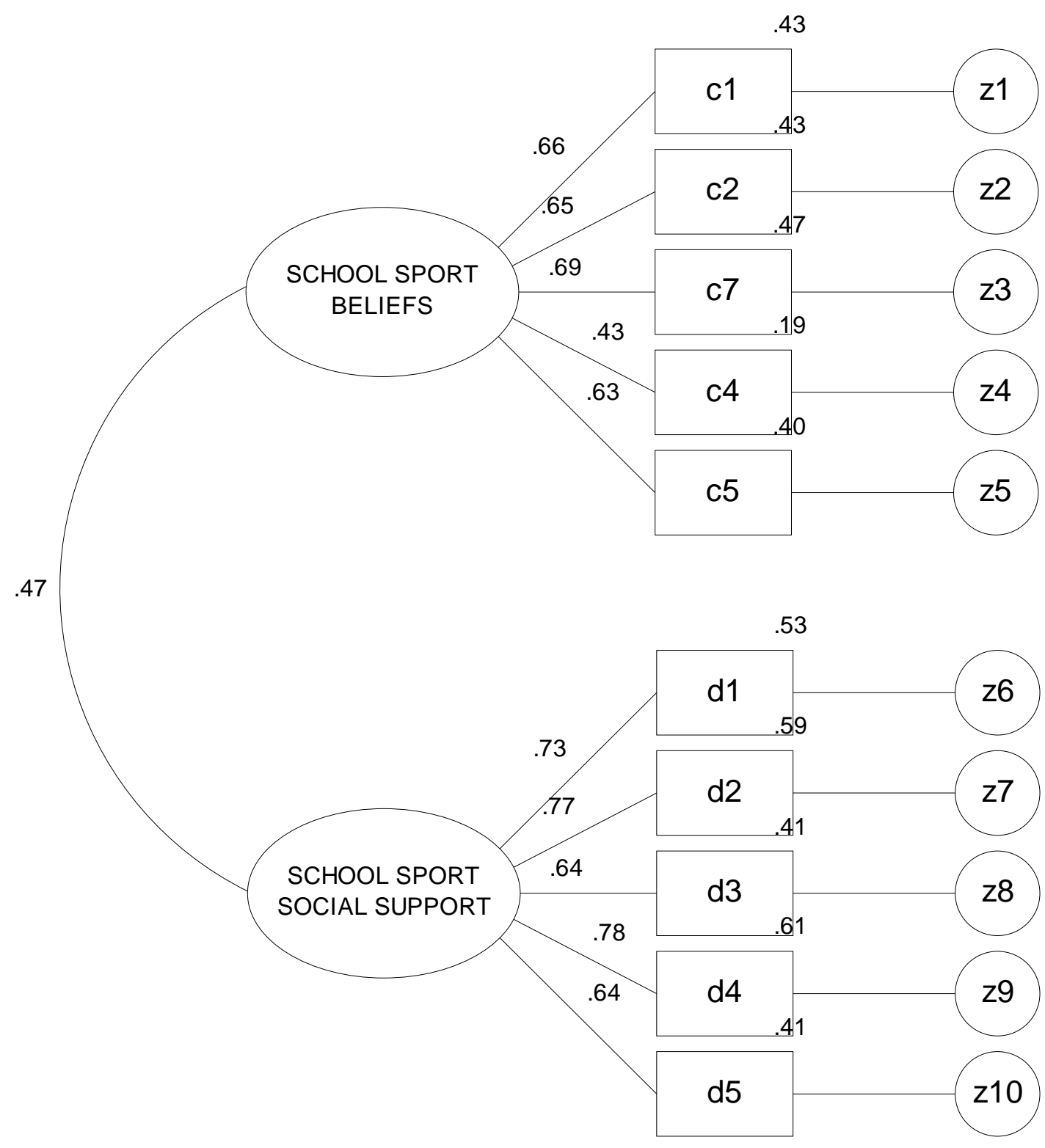

5 


\section{References}

Bandura, A. (1977). Self-efficacy: Toward a unifying theory of behavior change. Psychological Review, 84, 191-215.

Bandura, A. (1986). Social Foundations of Thought and Action: A Social Cognitive Theory. Englewood Cliffs, N.J: Prentice-Hall.

Bandura, A. (2004). Health promotion by social cognitive means. Health Education \& Behavior, 31, 143-164.

Barnett, L. M., Morgan, P. J., van Beurden, E., \& Beard, J. R. (2008). Perceived sports competence mediates the relationship between childhood motor skill proficiency and adolescent physical activity and fitness: a longitudinal assessment. International Journal of Behavioral Nutrition \& Physical Activity, 5, doi:10.1186/1479-5868-1185-1140.

Barnett, L. M., van Beurden, E., Morgan, P. J., Brooks, L. O., \& Beard, J. R. (2009). Childhood motor skill proficiency as a predictor of adolescent physical activity. Journal of Adolescent Health, 44, 252-259.

Biddle, S., \& Goudas, M. (1996). Analysis of children's physical activity and its association with adult encouragement and social cognitive variables. Journal of School Health, 66, 75-78.

Biddle, S., \& Mutrie, N. (2001). Psychology of Physical Activity: Determinants, Wellbeing and Interventions. London: Routledge.

Biddle, S. J. H. (2001). Enhancing motivation in physical education. In G. C. Roberts (Ed.), Advances in Motivation in Sport and Exercise (pp. 101-127). Champaign: Human Kinetics.

Biddle, S. J. H., Whitehead, S. H., O'Donovan, T. M., \& Nevill, M. E. (2005). Correlates of participation in physical activity for adolescent girls: A 
systematic review of recent literature. Journal of Physical Activity \& Health, 2, 423-434.

Castelli, D., \& Valley, J. (2007). The relationship of physical fitness and motor competence to physical activity. Journal of Teaching in Physical Education $26,358-374$

Centers for Disease Control \& Prevention. (1997). Guidelines for school and community programs to promote lifelong physical activity among young people. Morbidity \& Mortality Weekly Report, 45, 1-36.

Corbin, C. B. (2002). Physical activity for everyone: What every physical educator should know about promoting lifelong physical activity. Journal of Teaching in Physical Education, 21, 128-144.

Daley, A. J. (2002). Extra-curricular physical activities and physical self-perceptions in British 14-15-year-old male and female adolescents. European Physical Education Review, 8, 37-49.

Eklund, R. C., Whitehead, J. R., \& Welk, G. J. (1997). Validity of the children and youth Physical Self-Perception Profile: A confirmatory factor analysis. Research Quarterly for Exercise \& Sport, 68, 240-256.

Erwin, H. E., \& Castelli, D. M. (2008). National physical education standards: a summary of student performance and its correlates. Research Quarterly for Exercise \& Sport, 79, 495-505.

Fairclough, S. (2003). Physical activity, perceived competence and enjoyment during high school physical education. European Journal of Physical Education, 8, 518. 
1 Fairclough, S., Stratton, G., \& Baldwin, G. (2002). The contribution of secondary school physical education to lifetime physical activity. European Physical Education Review, 8, 69-84.

Fisher, A., Reilly, J. J., Kelly, L. A., Montgomery, C., Williamson, A., Paton, J. Y., et al. (2005). Fundamental movement skills and habitual physical activity in young children. Medicine \& Science in Sports \& Exercise, 37, 684-688.

Flintoff, A., \& Scraton, S. (2001). Stepping into active leisure? Young women's percetpions of active lifestyles and their experiences of school physical education. Sport, Education and Society, 6, 5-21.

Fox, K. R. (1988). The child's perspective in physical education. Part 1: The psychological dimension in physical education. British Journal of Physical Education, 19, 34-38.

Fox, K. R., \& Corbin, C. B. (1989). The Physical Self-Perception Profile: development and preliminary validation. Journal of Sport \& Exercise Psychology, 11, 408-430.

Fox, K. R., \& Corbin, C. B. (1990). The Physical Self-Perception Profile Manual. In K. R. Fox (Ed.), PRN Monograph (pp. 1-19). Northern Illinois: DeKalb, IL: University Office for Health Promotion.

Green, K. (2000). Exploring the everyday 'philosophies' of physical education teachers from a sociological perspective. Sport, Education and Society, 5, 109129.

Hill, G., \& Cleven, B. (2005). A comparison of 9th grade male and female physical education activities preferences and support for coeducational groupings. The Physical Educator,, 62, 187-198. 
1 Hill, G., \& Hannon, J. C. (2008). An analysis of middle school students' physical education physical activity preferences. Physical Educator, 65, 180.

Kimm, S. Y., Glynn, N. W., Kriska, A. M., Barton, B. A., Kromsberg, S. S., Daniels, S. R., et al. (2002). Decline in physical activity in black girls and white girls during adolescence. The New England Journal of Medicine, 347, 709-715.

Lubans, D. R., Foster, C., \& Biddle, S. J. H. (2008). A review of mediators of behavior in interventions to promote physical activity among children and adolescents. Preventive Medicine, 47, 463-470.

Lubans, D. R., \& Morgan, P. J. (2009). Social, psychological and behavioural correlates of pedometer step counts in a sample of Australian adolescents Journal of Science \& Medicine in Sport, 12, 141-147.

MacFadyen, T. (1999). An analysis of the influence of secondary school physical education on young people's attitudes towards physical activity. The Bulletin of Physical Education, 35, 157-171.

McDonald, N. C. (2007). Active transportation to school: trends among U.S. school children, 1969-2001. American Journal of Preventive Medicine, 32, 509-516.

Nader, P. R., Bradley, R. H., Houts, R. M., McRitchie, S. L., \& O’Brien, M. (2008). Moderate-to-vigorous physical activity from ages 9 to 15 years. Journal of the American Medical Association, 300, 295-305.

Okely, A., Booth, M. L., \& Patterson, J. W. (2001). Relationship of physical activity to fundamental movement skills among adolescents. Medicine \& Science in Sport \& Exercise, 33, 1899-1904.

Pate, R. R., Davis, M. G., Robinson, T. N., Stone, E. J., McKenzie, T. L., Young, J. C., et al. (2006). Promoting physical activity in children and youth. Circulation, 114, 1214-1224. 
1 Penney, D., \& Harris, J. (1997). Extra-curricular physical education: More of the same for the more able. Sport, Education and Society, 2, 45-54.

Rajmund, T. (2008). Students membership in school sports clubs and their attitudes towards physical education and sport in various types of schools. Human Movement, 9, 142-147.

Raudsepp, L., \& Pall, P. (2006). The relationship between fundamental motor skills and outside school physical activity of elementary school children. Pediatric Exercise Science, 18, 426-435.

Raustorp, A., Stahle, A., Gudasic, H., Kinnunen, A., \& Mattsson, E. (2005). Physical activity and self-perception in school children assessed with the Children and Youth - Physical Self-Perception Profile. Scandinavian Journal of Medicine and Science in Sports 15, 126-134

Rikard, G. L., \& Banville, D. (2006). High school student attitudes about physical education. Sport, Education \& Society, 11, 385-400.

Ross, J., Hartford, R., Crawford, S. A. G. M., \& Miller, J. (1997). Should interscholastic sports be abolished in the middle and high school levels. Journal of Physical Education, Recreation \& Dance, 68, 11-13.

Sallis, J. F., and McKenzie, T.L. (1991). Physical education's role in public health. Research Quarterly for Exercise and Sport, 62, 124-137.

Sallis, J. F., Prochaska, J. J., \& Taylor, W. C. (2000). A review of correlates of physical activity of children and adolescents. Medicine \& Science in Sports \& Exercise, 32, 963-975.

Santrock, J. W. (2005). Adolesence. Boston: McGraw-Hill.

Stodden, D., Goodway, J. D., Langendorfer, S., Roberton, M. A., Rudisill, M. E., Garcia, C., et al. (2008). A developmental perspective on the role of motor 
skill competence in physical activity: an emergent relationship. Quest, 60, 290-306.

Strong, W. B., Malina, R. M., Blimkie, C. J., Daniels, S. R., Dishman, R. K., Gutin, B., et al. (2005). Evidence based physical activity for school-age youth. Journal of Pediatrics, 146, 732-737.

Van der Horst, K., Paw, M. J. C. A., Twisk, J. W. R., \& Van Mechelen, W. (2007). A brief review on correlates of physical activity and sedentariness in youth. Medicine \& Science in Exercise \& Sport, 39, 1241-1250.

Van der Ploeg, H. P., Merom, D., Corpuz, G., \& Bauman, A. E. (2008). Trends in Australian children traveling to school 1971-2003: Burning petrol or carbohydrates? Preventive Medicine, 46, 60-62.

Wallhead, T. L., \& Buckworth, J. (2004). The role of physical education in the promotion of youth physical activity. Quest, 56 285-301.

Wang, C. K., Lim, B. S. C., Aplin, N. G., Chia, Y. H. M., McNeill, M., \& Tan, W. K. C. (2008). Students' attitudes and perceived purposes of physical education in Singapore: Perspectives from a 2 x 2 achievement goal framework. European Physical Education Review 14, 51-70.

Wechsler, H., Devereaux, R. S., Davis, M., \& Collins, J. (2000). Using the school environment to promote physical activity and healthy eating. Preventive Medicine, 31, S121-S137.

Westerterp, K. R., \& Speakman, J. R. (2008). Physical activity energy expenditure has not declined since the 1980s and matches energy expenditures of wild mammals. International Journal of Obesity, 32, 1256-1263. 
1 Wrotniak, B. H., Epstein, L. H., Dorn, J. M., Jones K.E., \& Kondilis, V. A. (2006).

2 The relationship between motor proficiency and physical activity in children. Pediatrics 118, e1758-e1765.

4 Zakarian, J. M., Hovell, M. F., Hofstetter, C. R., Sallis, J. F., \& Keating, K. J. (1994). Correlates of vigorous exercise in a predominantly low SES and minority high school population. Preventive Medicine, 23, 314-321.

7

8

9 